\title{
PENGARUH BAURAN PEMASARAN TERHADAP LOYALITAS PELANGGAN RESTORAN WAROENG HOTPLATE ODON BOGOR
}

\author{
Tasya Amanda ${ }^{1}$, Rita Nurmalina ${ }^{2}$, dan Siti Jahroh ${ }^{3}$ \\ 1)Program Magister Sains Agribisnis, Sekolah Pascasarjana, Institut Pertanian Bogor \\ 2)Departemen Agribisnis, Fakultas Ekonomi dan Manajemen, Institut Pertanian Bogor \\ Jl. Kamper Wing 4 Level 5 Kampus IPB Dramaga, Indonesia \\ 3) Sekolah Bisnis Institut Pertanian Bogor \\ Kampus IPB Gunung Gede, Jl. Raya Pajajaran Bogor, Indonesia \\ e-mail: 1)tasyatobing1195@gmail.com
}

(Diterima 10 Desember 2019/ Revisi 14 Januari 2020 /Disetujui 19 Januari 2020)

\begin{abstract}
Currently, Indonesia has a 265 million population in which more than one-third of the population is the modern generation who are more likely to have a preference for something that simple and practical like taking a meal in the restaurant. Bogor is one of the cities generally known for its culinary varieties. Waroeng Hotplate Odon is one of them which uniquely serves dishes, which uses hot plates and has a spiciness level and its sales experienced a downward trend due to high competition among the restaurants. This research aims to analyze the effect of marketing mix consist of $7 P$ variables which are: product, promotion, place, price, people, process and physical evidence towards customer satisfaction and customer loyalty of Waroeng Hotplate Odon restaurant. The sample of the research is 393 people who visited Waroeng Hotplate Odon restaurant. The sampling method applied in this study is purposive sampling using a questionnaire distributed to Waroeng Hotplate Odon visitors. The structural Equation Modeling (SEM) method is used to analyze the data. This research showed that 4 variables affect customer satisfaction and loyalty of Waroeng Hotplate Odon visitors, which are price, process and physical evidence. The satisfaction variable has a significant effect on consumer loyalty, which is reflected by consumers' willingness to make repeat purchases and recommend restaurants to other parties. In general, respondents feel satisfied and loyal to the restaurant. Based on the result of the study, the following strategies to increase customer loyalty of Waroeng Hotplate Odon are improving the quality of flavour, spiciness level, variety of the menu, offering menu with more affordable prices, improving restaurant's layout and parking spaces, and implementing a service system based on Standard Operating Procedures (SOP).
\end{abstract}

Keywords: customer satisfaction, marketing mix $7 P$, structural equation model

\begin{abstract}
ABSTRAK
Indonesia saat ini memiliki 265 juta jiwa penduduk, dimana lebih dari sepertiganya merupakan generasi modern yang memiliki preferensi dalam melakukan hal-hal yang praktis, salah satunya melakukan aktivitas makan di luar. Bogor merupakan salah satu kota yang dikenal dengan kulinernya. Waroeng Hotplate Odon adalah salah satu restoran yang menyajikan hidangan dengan cara unik yaitu menggunakan piring panas dan memiliki tingkat kepedasan dan penjualanya mengalami tren menurun. Penelitian ini bertujuan untuk menganalisis pengaruh dari bauran pemasaran yang terdiri dari 7P yaitu variabel produk, promosi, lokasi, harga, pelaku, proses, dan bukti fisik terhadap kepuasan dan loyalitas pengunjung Waroeng Hotplate Odon. Sampel penelitian ini berjumlah 393 orang yang merupakan pengunjung Waroeng Hotplate Odon. Metode penarikan sampel pada penelitian ini adalah purposive sampling dengan menggunakan kuesioner yang disebar kepada pengunjung Waroeng Hotplate Odon. Pada penelitian ini digunakan metode Model Persamaan Struktural (SEM) untuk melakukan analisis data. Hasil penelitian menunjukkan bahwa terdapat 4 variabel yang memengaruhi kepuasan dan loyalitas pengunjung Waroeng Hotplate Odon yaitu produk, harga, proses dan bukti fisik. Variabel kepuasan berpengaruh signifikan terhadap loyalitas konsumen yang direfleksikan oleh kesediaan konsumen dalam melakukan pembelian ulang dan merekomendasikan restoran kepada pihak lain. Beberapa strategi untuk meningkatkan loyalitas pelanggan Waroeng Hotplate Odon yaitu peningkatan kualitas citarasa hidangan, peningkatan level kepedasan, penambahan
\end{abstract}


variasi makanan, penetapan harga yang lebih terjangkau, perbaikan tata ruang restoran, manajamen lahan parkir dan penerapan sistem pelayanan berdasarkan Standar Operasional Prosedur (SOP).

Kata kunci: bauran pemasaran 7P, kepuasan konsumen, model persamaan struktural

\section{PENDAHULUAN}

Indonesia merupakan negara dengan populasi penduduk terbesar ke-4 di dunia, yakni dengan jumlah penduduk sebanyak 265 juta jiwa (Bappenas 2018). Dari angka tersebut, sebesar 33,75 persennya merupakan penduduk usia muda yang lahir di antara tahun 1980 sampai 2000 yang saat ini dikenal sebagai generasi milenial (Kuhns dan Saksena 2016). Proporsi tersebut merupakan jumlah terbesar dibandingkan kelompok usia lainnya. Di era modern, generasi milenial memberi pengaruh yang besar terhadap gaya hidup masyarakat Indonesia. Hal ini disebabkan generasi milenial dalam menentukan pilihan banyak dipengaruhi oleh munculnya ponsel pintar, meluasnya internet, dan berbagai macam aplikasi serta media sosial (Doub et al. 2015). Berbeda dengan generasi lainnya, generasi milenial memiliki pengaruh yang tinggi dalam menyebarkan tren (Barnes 2015). Menurut Debora (2017), generasi ini aktif menggunakan media sosial untuk menyebarkan informasi mengenai preferensi mereka terhadap barang dan jasa.

Restoran sebagai jasa penyedia makanan dan minuman merupakan proporsi tertinggi bagi generasi milenial Indonesia dalam membelanjakan pendapatannya dibandingkan dengan pembelian bahan makanan, bahan bakar, obat-obatan dan lainnya menurut Debora (2017). Kecenderungan masyarakat dalam mengunjungi restoran dibandingkan makan di rumah merupakan salah satu ciri masyarakat yang menyukai hidup serba praktis. Saulo (2016) menyebutkan bahwa milenial mencari pengalaman baru sebagai salah satu pertimbangan memilih tempat makan.

Bogor sebagai salah satu daerah yang memiliki daya tarik di bidang kuliner kini sangat diminati oleh para pencinta kuliner, terutama generasi milenial. Bogor disebut sebagai kawasan kuliner karena terdapat banyak restoran, kafe, dan kedai-kedai penyedia makanan dan minuman. Semakin banyaknya permintaan terhadap jasa penyedia kuliner, jumlah industri kuliner mengalami peningkatan sehingga persaingan antar restoran semakin tinggi.

Makanan pedas menjadi salah satu tren yang sering dijumpai ketika berkunjung ke berbagai pusat kuliner. Tren makanan pedas dapat dilihat dari prediksi konsumsi cabai dan sambal olahan dari tahun 2018 hingga 2023 yang diperkirakan akan tumbuh di atas 6 persen setiap tahunnya menurut Fazira (2019).

Restoran Waroeng Hotplate Odon adalah salah satu dari banyaknya restoran di Bogor yang menyediakan ragam masakan dengan cita rasa pedas. Menu utama yang terdapat di restoran ini adalah mie yang disajikan dengan alas hotplate. Restoran yang berdiri sejak tahun 2015 ini terdiri dari 8 cabang dan memiliki banyak peminat.

Jumlah pengunjung Restoran Waroeng Hotplate Odon mengalami tren menurun menurut data penjualan lima periode terakhir. Penurunan jumlah pengunjung secara signifikan menyebabkan penurunan pendapatan restoran. Hal ini dapat dipengaruhi oleh berbagai hal, salah satunya akibat rendahnya loyalitas konsumen Waroeng Hotplate Odon. Menurut Lam dan Burton (2006), loyalitas dapat dipengaruhi oleh berbagai macam hal salah satunya kepuasan.

Kepuasan konsumen dapat ditentukan dengan menilai keseluruhan layanan yang diberikan oleh restoran. Jika pelayanan dinilai positif, dapat dikatakan konsumen merasa puas terhadap pelayanan yang restoran berikan. Kita dapat melihat pelayanan secara keseluruhan dengan memperhatikan bauran pemasaran. Bauran pemasaran pada sebuah 
jasa terdiri dari 7P yaitu produk, harga, lokasi, promosi, kondisi fisik, pelaku dan proses (Lovelock dan Wirtz 2011). Berdasarkan uraian di atas, rumusan permasalahan dalam penelitian ini adalah sebagai berikut. 1) Bagaimana pengaruh bauran pemasaran (7P) terhadap kepuasan restoran? 2) Apakah kepuasan berpengaruh terhadap loyalitas restoran? 3) Apa saja strategi yang dapat dilakukan untuk meningkatkan kepuasan dan loyalitas?

\section{METODE}

\section{LOKASI DAN WAKTU PENELITIAN}

Penelitian dilakukan di Restoran Waroeng Hotplate Odon yang berlokasi di Bogor. Pemilihan lokasi penelitian dilakukan secara sengaja dengan pertimbangan bahwa Waroeng Hotplate Odon ini merupakan restoran yang memiliki menu utama berupa makanan dengan citarasa pedas yang khas dan disajikan dengan cara yang unik. Selain itu, lokasinya strategis dan sering dilalui oleh pengguna jalan. Waktu penelitian dilakukan pada bulan Februari hingga April 2019.

\section{METODE PENENTUAN SAMPEL}

Metode penarikan sampel yang dilakukan pada penelitian ini yaitu dengan metode purposive sampling. Purposive sampling adalah teknik pengambilan sampel berdasarkan kriteria yang telah dirumuskan terlebih dahulu oleh peneliti (Nazir 2005). Kriteria responden dalam penelitian ini yaitu telah mengunjungi Waroeng Hotplate Odon minimal sebanyak dua kali karena diperlukan pengalaman makan di lokasi penelitian untuk dapat memberikan penilaian mengenai restoran. Penentuan responden dibatasi hanya yang telah berusia 17 tahun ke atas dengan pertimbangan bahwa di usia tersebut responden dapat berpikir secara stabil. Responden yang digunakan dalam penelitian ini berjumlah 393 orang, sesuai dengan persyaratan minimum atas alat analisis yang digunakan. Menurut Hair et. al (1998) jumlah sampel yang diambil dari populasi ditentukan sebesar 5-10 kali jumlah indikator yang digunakan dalam desain analisis, sekurang-kurangnya sebanyak 100-200 sampel. Jumlah variabel yang digunakan dalam penelitian ini adalah 27 indikator yang merupakan total dari variabel laten eksogen dan endogen. Oleh karena itu, jumlah responden adalah 5 kali jumlah indikator sehingga diperoleh syarat minimum 135 responden.

\section{METODE ANALISIS DATA}

Metode pengolahan data dalam penelitian ini dilakukan secara kualitatif dan kuantitatif. Pengolahan data kualitatif dilakukan dengan menggunakan Microsoft Excel 2016 untuk tabulasi data deskriptif sementara untuk uji pretest validitas dan reliabilitas menggunakan SPSS 16.0. Uji kuantitatif diolah menggunakan LISREL untuk menganalisis Model Persamaan Struktural (SEM).

\section{MODEL PERSAMAAN STRUKTURAL (SEM)}

Indikator variabel eksogen yang berasal dari bauran pemasaran dihubungkan dengan variabel laten endogen yaitu kepuasan dan loyalitas. Variabel ini diolah dan dianalisis dengan metode Model Persamaan Struktural (SEM) yaitu Covariance-Based Structural Equation Modeling (CB-SEM) untuk mengestimasi model struktural berdasarkan teori, yakni menguji hubungan kausalitas antar konstruk serta mengukur kelayakan model dan mengonfirmasi sesuai dengan data empirisnya. Prosedur Model Persamaan Struktural secara umum menurut Latan (2013) adalah sebagai berikut.

\section{Spesifikasi Model}

Pada tahap ini peneliti harus mendefinisikan secara konseptual konstruk yang diteliti dan menentukan dimensionalitasnya. Selanjutnya, arah kausalitas antar konstruk yang menunjukkan hubungan harus ditentukan dengan jelas serta berdasarkan landasan teori yang kuat. 


\section{Identifikasi Model}

Identifikasi model penting untuk mengetahui apakah model yang dibangun dengan data empiris tersebut memiliki nilai yang unik atau tidak sehingga model tersebut dapat diestimasi. Jika model tidak memiliki nilai yang unik, model tersebut tidak dapat diidentifikasi (unidentified).

\section{Estimasi Model}

Sebelum mengestimasi model, penting untuk menentukan metode estimasi yang digunakan dan mempertimbangkan besarnya jumlah sampel yang dibutuhkan karena hal tersebut akan berpengaruh terhadap interpretasi hasil analisis. Ukuran sampel yang disarankan untuk penggunaan estimasi model adalah sebesar 100-200.

Setelah menentukan metode estimasi, langkah selanjutnya untuk mengestimasi model adalah menentukan jumlah sampel yang harus dipenuhi. Bentler dan Chou (1987) merekomendasikan jumlah sampel yang harus dipenuhi untuk estimasi SEM adalah 5 parameter yang akan diestimasi.

\section{Evaluasi Model}

Evaluasi model bertujuan untuk mengevaluasi model secara keseluruhan, apakah model mempunyai fit yang baik atau tidak. Evaluasi model dalam CB-SEM dapat dilakukan dengan menilai hasil pengukuran model (measurement model) yaitu melalui analisis faktor konfirmatori atau confirmatory factor analysis (CFA) dengan menguji validitas dan reliabilitas konstruk laten kemudian dilanjutkan dengan evaluasi model struktural secara keseluruhan dengan menilai kelayakan model melalui kriteria goodness of fit. Beberapa indeks kesesuaian dan cut of value yang umumnya digunakan adalah sebagai berikut.

a. Degree of Freedom (DF) harus positif yang menandakan model tidak underidentified.

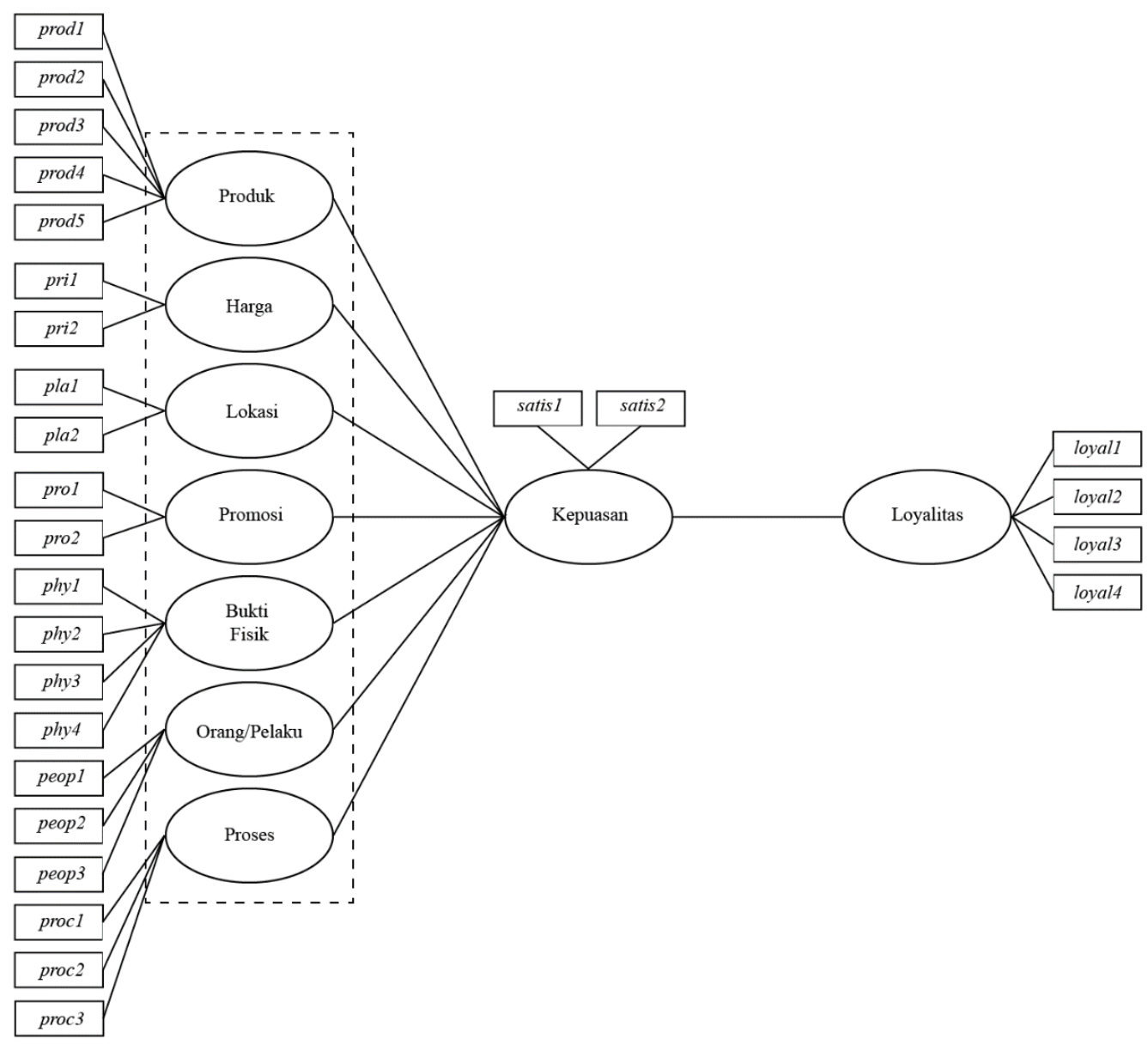

Gambar 1. Model Persamaan Struktural dalam Diagram Jalur 
b. P-value harus lebih dari 0.05 untuk menunjukkan bahwa uji kecocokan model yang dilakukan telah memenuhi ketentuan yang disyaratkan.

c. RMSEA (Root Mean Square Error of Approximation) adalah indeks untuk mengkompensasikan chi-square dalam contoh besar yang menunjukkan kesesuaian yang diharapkan bila model diestimasi. Syarat agar model menunjukkan close fit adalah RMSEA $<0.08$.

d. GFI (Goodness of Fit $=$ R2 dalam regresi) adalah rentang ukuran antara 0 (poor fit) sampai dengan 1 (perfect fit) yang memperhitungkan proporsi tertimbang dari varian dalam sebuah matriks kovarian. Nilai GFI good fit jika $\geq 0,90$.

e. CFI (Comparative Fit Index) merupakan indeks yang besarannya tidak dipengaruhi oleh ukuran contoh. Nilai disarankan $\geq$ 0,90 untuk menunjukkan kecocokan incremental.

\section{Interpretasi dan Modifikasi Model}

Setelah model diterima, dilakukan interpretasi dengan mengikuti teori yang mendasari. Modifikasi model dilakukan jika kriteria kelayakan model belum sesuai, yaitu dengan membuang atau menambah hubungan di dalam model SEM. Modifikasi hanya dapat dilakukan jika terdapat perubahan yang signifikan dengan dukungan data empirik.

\section{HASIL DAN PEMBAHASAN}

\section{ANALISIS MODEL PENGUKURAN}

Analisis Model Pengukuran atau confirmatory factor analysis adalah sebuah analisis yang digunakan untuk mengamati hubungan antara variabel teramati (indikator) dengan variabel laten (konstruk) dimana variabel teramati adalah refleksi dari variabel tersebut. Terdapat tiga jenis analisis dalam model pengukuran pada penelitian ini yaitu 1) Uji kecocokan keseluruhan model pengukuran atau goodness of fit dengan melihat beberapa parameter parameter, uji ini dilakukan untuk melihat kecocokan antara data dan model, 2) Uji Validitas, uji validitas digunakan untuk melihat ketepatan variabel teramati menggambarkan variabel latennya, parameter yang digunakan untuk melihat validitasnya adalah nilai dari t-value dan SLF (Wijanto 2008), 3) Uji Reliabilitas, uji ini dilakukan untuk melihat konsistensi variabel teramati menggambarkan variabel latennya, dalam mengukur reliabilitas parameter yang diperhatikan adalah nilai dari construct reliability dan variance extracted (Wijanto 2008). Berikut adalah analisis dari model pengukuran penelitian ini.

\section{METODE GOODNESS OF FIT KESELURUHAN MODEL PENGUKURAN}

Tabel 1 adalah hasil analisis goodness of fit keseluruhan model pengukuran hasil pengolahan data menggunakan LISREL 8,51.

Hasil analisis goodness of fit keseluruhan model yang terdapat pada Tabel 1 dijabarkan lebih rinci pada tiap parameter di bawah ini.

a. Degree of Freedom (DF) hasil model pengukuran ini bernilai 295. Nilai tersebut menunjukkan bahwa model ini tidak underidentified.

b. P-Value dari model ini menunjukkan angka 0,64. Nilai tersebut menandakan model memiliki nilai kecocokan model yang baik karena nilainya lebih besar dari syarat 0,05 .

Tabel 1. Goodness of Fit Keseluruhan Model Pengukuran

\begin{tabular}{llrc}
\hline \multicolumn{1}{c}{ Ukuran Goodness of Fit } & \multicolumn{1}{c}{ Syarat Good Fit } & Nilai & Keterangan \\
\hline Degree of Freedom & Positif & 295 & Good Fit \\
P-value for Test Close Fit & $>0,05$ & 0,64 & Good Fit \\
Root mean square error of & $\leq 0,05=$ close fit. & 0,033 & Close Fit \\
approxiamton (RMSEA) & $\geq 0,05$ hingga $\leq 0.08=$ good fit. & 0,97 & Good Fit \\
Goodness of fit index (GFI) & $>0,90$ & 1,00 & Good Fit \\
Comparative fit index (CFI) & $>0,90$ & & \\
\hline
\end{tabular}


c. Model bersifat good fit dilihat dari goodness of fit index (GFI), pada model ini nilai GFI adalah 0,97 dimana untuk menjadi model yang good fit nilai dari GFI $\geq 0,9$.

d. Nilai dari Root mean square error of approximation (RMSEA) adalah 0,033. Nilainya yang < 0,05 menunjukkan bahwa RMSEA pada model ini close fit.

e. Minimum good fit jika nilai indeks $\geq 0,9$, dengan kata lain bahwa model ini good fit karena nilai dari comparative fit index (CFI) bernilai 0,99.

Dari beberapa indikator yang digunakan untuk mengukur kecocokan model struktural, tidak ada satupun yang menunjukkan poor fit. Ketika tidak ada poor fit, dan mayoritas adalah good fit, dapat dikatakan bahwa secara keseluruhan model memiliki kecocokan model yang baik.

\section{UJI VALIDITAS DAN RELIABILITAS INDIKATOR VARIABEL}

Untuk mengetahui apakah sebuah variabel dapat digambarkan dengan baik oleh indikatornya, terdapat dua parameter nilai yang perlu diperhatikan yaitu nilai yang mewakilkan kesuluruhan variabel dan juga per indikator. Jika seluruh parameter ini terpenuhi, dapat dikatakan indikator dapat menggambarkan variabel laten dengan baik. Adapun parameter tersebut adalah sebagai berikut.

1. Standardized loading factor adalah besaran korelasi antara indikator dan variabel latennya. Indikator yang memiliki loading factor yang semakin tinggi dapat dikatakan lebih bias menggambarkan variabel latennya. Sebuah indikator dikatakan valid jika memiliki SLF > 0,5 (Wijanto 2008).

2. T-Value adalah indikator untuk menunjukkan sebuah variabel valid. Sebuah indika-

Tabel 2. Uji Validitas dan Reliabilitas Variabel

\begin{tabular}{|c|c|c|c|c|c|c|}
\hline $\begin{array}{c}\text { Variabel } \\
\text { Laten }\end{array}$ & Indikator & T-Value & SLF & Error & $\begin{array}{l}\text { Construct } \\
\text { Reliability }\end{array}$ & $\begin{array}{l}\text { Variance } \\
\text { Extracted }\end{array}$ \\
\hline \multirow{5}{*}{ Produk } & Prod1 (citarasa lezat) & 31,76 & 0,97 & 0,06 & \multirow{5}{*}{0,923} & \multirow{5}{*}{0,708} \\
\hline & Prod2 (porsi cukup) & 29,11 & 0,78 & 0,39 & & \\
\hline & Prod3 (tampilan menu menarik) & 29,36 & 0,79 & 0,38 & & \\
\hline & Prod4 (menu variative) & 28,14 & 0,80 & 0,36 & & \\
\hline & Prod5 (tingkat kepedasan sesuai) & 33,28 & 0,85 & 0,28 & & \\
\hline \multirow[t]{2}{*}{ Harga } & Pri1 (harga terjangkau) & 13,91 & 0,89 & 0,21 & \multirow{2}{*}{0,724} & \multirow{2}{*}{0,576} \\
\hline & Pri2 (harga sesuai porsi) & 12,78 & 0,60 & 0,64 & & \\
\hline \multirow[t]{2}{*}{ Lokasi } & Pla1 (lokasi mudah dicapai) & 11,44 & 0,96 & 0,08 & \multirow{2}{*}{0,769} & \multirow{2}{*}{0,635} \\
\hline & Pla2 (banyak cabang) & 11,45 & 0,59 & 0,65 & & \\
\hline \multirow[t]{2}{*}{ Promosi } & Pro1 (iklan menarik) & 13,39 & 0,75 & 0,44 & \multirow{2}{*}{0,683} & \multirow{2}{*}{0,519} \\
\hline & Pro2 (potongan harga) & 13,89 & 0,69 & 0,52 & & \\
\hline \multirow[t]{4}{*}{ Bukti Fisik } & Phy1 (lahan parkir) & 22,43 & 0,85 & 0,28 & \multirow{4}{*}{0,780} & \multirow{4}{*}{0,593} \\
\hline & Phy2 (tata ruang) & 23,92 & 0,92 & 0,15 & & \\
\hline & Phy3 (fasilitas lain) & 18,72 & 0,63 & 0,60 & & \\
\hline & Phy4 (layanan pembayaran non tunai) & 20,39 & 0,64 & 0,59 & & \\
\hline \multirow[t]{3}{*}{ Pelaku } & Peop1 (karyawan ramah) & 20,21 & 0,60 & 0,64 & \multirow{3}{*}{0,860} & \multirow{3}{*}{0,672} \\
\hline & Peop2 (karyawan sigap) & 19,50 & 0,83 & 0,31 & & \\
\hline & Peop3 (karyawan bersih dan rapi) & 18,73 & 0,78 & 0,39 & & \\
\hline \multirow[t]{3}{*}{ Proses } & Proc1 (kecepatan pemesanan) & 21,50 & 0,84 & 0,29 & \multirow{3}{*}{0,860} & \multirow{3}{*}{0,673} \\
\hline & Proc2 (kecepatan penyajian) & 20,67 & 0,80 & 0,36 & & \\
\hline & Proc3 (kecepatan pembayaran) & 19,38 & 0,82 & 0,33 & & \\
\hline \multirow[t]{2}{*}{ Kepuasan } & Satis1 (sesuai harapan) & - & 0,79 & 0,38 & \multirow{2}{*}{0,786} & \multirow{2}{*}{0,648} \\
\hline & Satis2 (secara umum puas) & 12,90 & 0,82 & 0,33 & & \\
\hline \multirow[t]{4}{*}{ Loyalitas } & Loyal1 (pembelian ulang) & - & 0,83 & 0,31 & \multirow{4}{*}{0,817} & \multirow{4}{*}{0,533} \\
\hline & Loyal2 (tetap membeli saat harga naik) & 15,82 & 0,63 & 0,60 & & \\
\hline & Loyal3 (merekomendasi) & 16,55 & 0,83 & 0,31 & & \\
\hline & Loyal4 (mengadvokasi) & 14,78 & 0,60 & 0,64 & & \\
\hline
\end{tabular}


tor dikatakan valid jika memiliki T-Value > 1,96 (Wijanto 2008).

3. Construct Reliability adalah sebuah indikator untuk mengukur konsistensi antara indikator-indikator sebuah variabel laten. Sebuah variabel dikatakan reliabel ketika nilai construct realibilitynya $>0,7$ (Wijanto 2008).

4. Variance Extracted (VE) mencerminkan total varian secara keseluruhan pada indikatornya yang dijelaskan oleh variabel latennya. Semakin besar nilai VE maka reliabilitas variabel laten juga semakin besar. Sebuah variabel dikatakan reliabel jika memliki nilai Variance Extracted > 0,5 (Wijanto 2008).

Untuk mengetahui apakah indikator dan variabel dapat menggambarkan model dengan baik, masing-masing indikator dan variabel perlu dicocokkan dengan parameter yang telah disebutkan sebelumnya.

1. Standardized loading Factor : Berdasarkan Tabel 2, keseluruhan indikator memiliki nilai $>0,5$ sehingga dapat dikatakan indikator dari model ini valid dan dapat menggambarkan masing-masing variabelnya.

2. T-Value : Sama seperti standardized loading factor, T-Value dari setiap indikator memiliki nilai $>1,96$. Nilai tersebut telah memenuhi syarat indikator valid.

3. Construct reliability dari Tabel 2 menunjukkan bahwa mayoritas variabel memiliki CR $>0,7$. Walaupun terdapat satu variabel yang nilainya kurang dari 0,7, namun masih bisa digunakan karena tidak terpaut jauh dari syarat.

4. Variance Extracted pada seluruh variabel bernilai > 0,5 menunjukkan bahwa setiap indikator dapat menggambarkan variabelnya secara reliabel.

Berdasarkan hasil di atas, dapat disimpulkan bahwa seluruh variabel yang digunakan dalam model valid dan reliabel.

\section{ANALISIS HUBUNGAN KAUSAL}

Untuk dapat mengetahui pengaruh antara variabel independen terhadap variabel latennya, kita dapat melakukan hubungan kausal dengan melihat dari nilai dari T-Value. Analisis ini juga dinamakan path analysis karena memperhatikan jalur hubungan antar variabel. Berikut ini adalah analisis pengaruh variabel independen terhadap variabel dependen penelitian.

Pada Gambar 2 kita dapat melihat bahwa terdapat variabel yang bernilai merah dan hitam. Sebuah variabel dapat dikatakan secara signifikan berpengaruh terhadap variabel lainnya jika nilai T-value dari variabel tersebut lebih dari 1,96 yang ditandai dengan warna hitam. Jika kita melihat Gambar 2, terdapat empat variabel bauran pemasaran yang memiliki nilai $>1,96$ dan tiga variabel yang bernilai $<1,96$.

Agar hasil penelitian ini dapat bermanfaat untuk meningkatkan loyalitas konsumen Waroeng Hotplate Odon, perlu diperhatikan indikator apa saja yang paling berpengaruh signifikan terhadap variabel bauran pemasaran. Dengan mengetahui indikator yang paling berpengaruh, Waroeng Hotplate Odon dapat memprioritaskan variabel yang perlu diperbaiki dalam memberikan pelayanan.

Gambar 3 menjelaskan tentang standardized loading factor dari masing-masing indikator. Semakin besar nilai standardized loading factor, indikator tersebut menjadi prioritas perbaikan Waroeng Hotplate Odon. Dengan melihat Gambar 2 dan Gambar 3, didapatkan hasil perbandingan yang dirangkum pada Tabel 3.

Tabel 3 menginformasikan bahwa nilai produk memiliki pengaruh yang paling besar. Hal ini menunjukkan bahwa Waroeng Hotplate Odon perlu fokus di dalam meningkatkan kualitas hal yang berkenaan dengan produk. Hal yang perlu diperhatikan dari Waroeng Hotplate Odon adalah citarasa makanan, citarasa makanan perlu ditingkatkan dengan mencoba berbagai macam bumbu 


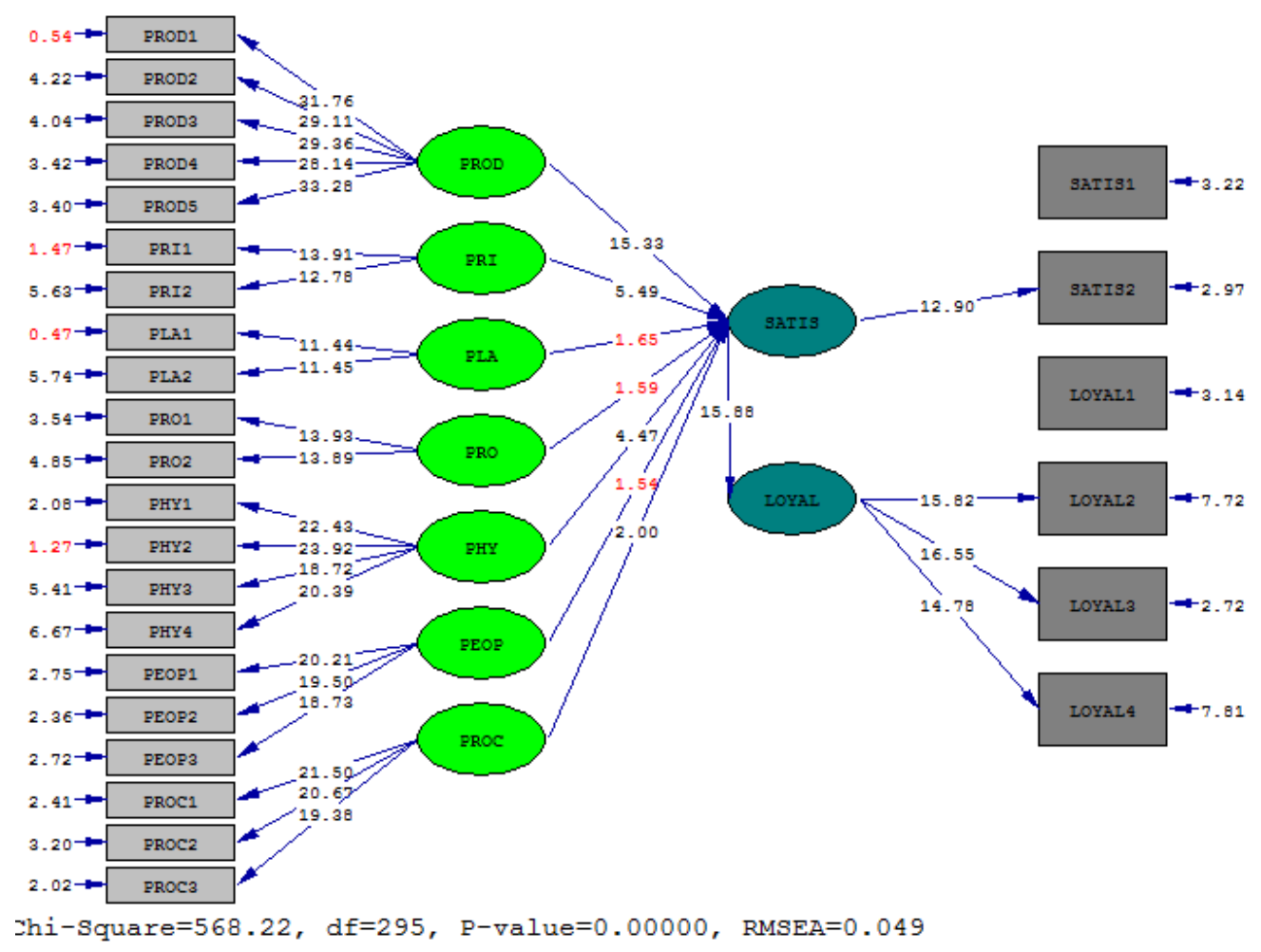

Gambar 2. Hasil Analisis Hubungan Kausal

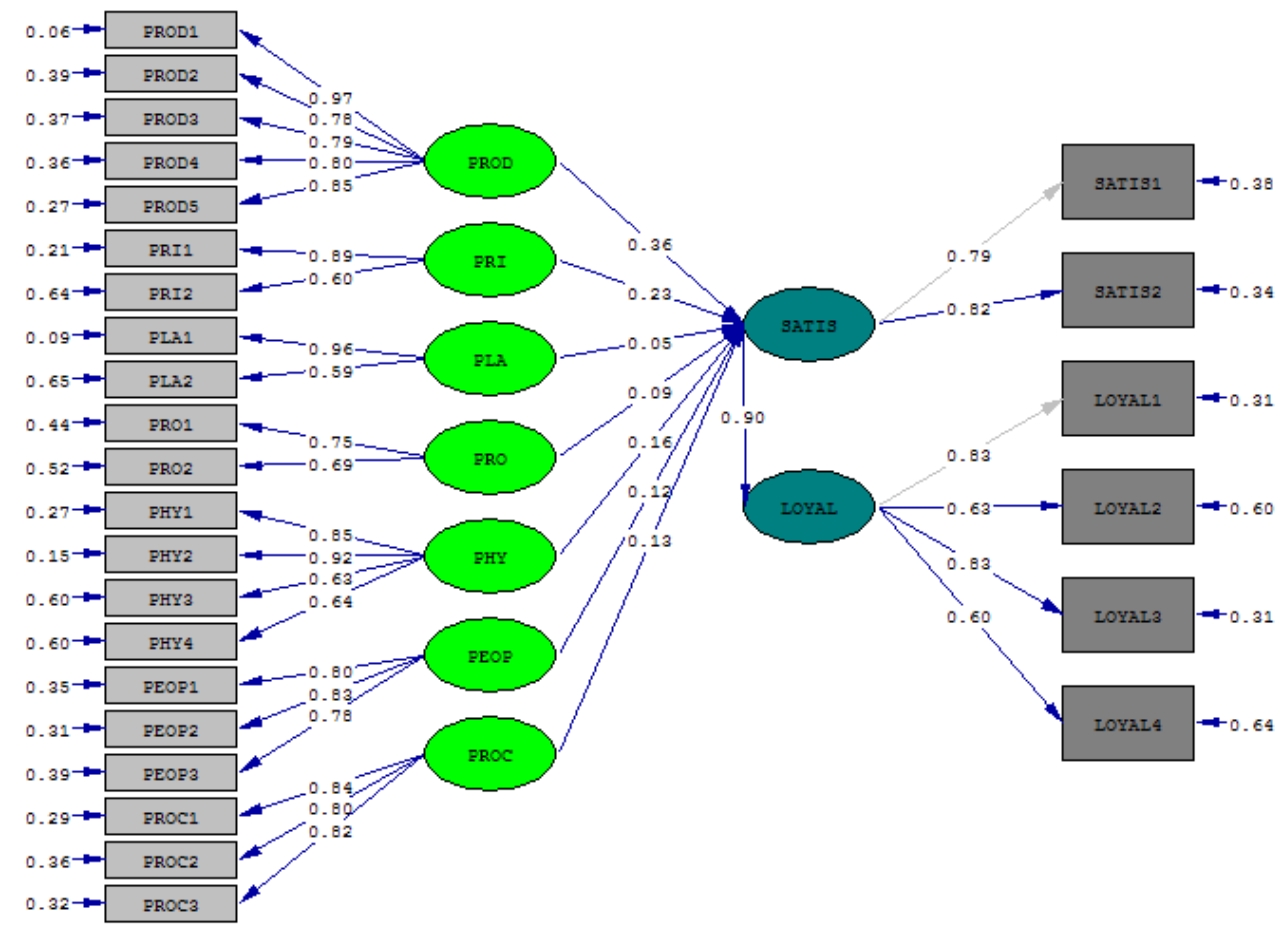

Gambar 3. Hasil Analisis Standardized Loading Factor

baru namun tetap menonjolkan kepadasan sebagai daya tarik utamanya. Kepedasan menjadi indikator selanjutnya yang berpengaruh terhadap produk, oleh karena itu level kepedasannya perlu dikembangkan lagi dari semula berkisar 1-5 level menjadi 1-10 agar dapat memuaskan penggemar makanan pedas. Hal lainnya yang bisa di kembangkan 
Tabel 3. SLF Indikator dari T-value Variabel Berpengaruh

\begin{tabular}{|c|c|c|c|c|}
\hline $\begin{array}{l}\text { Variabel } \\
\text { Laten }\end{array}$ & T-Value & Indikator & & SLF \\
\hline \multirow{5}{*}{ Produk } & 15,33 & Prod1 & Citarasa hidangan lezat & 0,97 \\
\hline & & Prod2 & Porsi makanan cukup & 0,78 \\
\hline & & Prod3 & Tampilan menu menarik & 0,79 \\
\hline & & Prod4 & Pilihan menu bervariasi & 0,80 \\
\hline & & Prod5 & Tingkat kepedasan sesuai & 0,85 \\
\hline \multirow[t]{2}{*}{ Harga } & 5,49 & Pri1 & Harga terjangkau & 0,89 \\
\hline & & Pri2 & Harga sesuai porsi & 0,60 \\
\hline \multirow[t]{4}{*}{ Bukti Fisik } & 4,47 & Phy1 & Lahan parkir mencukupi & 0,85 \\
\hline & & Phy2 & Penataan ruang baik & 0,92 \\
\hline & & Phy3 & Fasilitas memadai (toilet, wastafel, dan mushala) & 0,63 \\
\hline & & Phy4 & Tersedialayanan pembayaran non tunai & 0,64 \\
\hline \multirow[t]{3}{*}{ Proses } & 2,00 & Proc1 & Pelayanan dalam pemesanan menu cepat & 0,84 \\
\hline & & Proc2 & Pelayanan dalam penyajian hidangan cepat & 0,80 \\
\hline & & Proc3 & Pelayanan dalam proses pembayaran cepat & 0,82 \\
\hline
\end{tabular}

oleh Waroeng Hotplate Odon yaitu terkait variasi makanan dengan menawarkan berbagai macam jenis sambal, seperti sambal geprek, sambal matah dan jenis sambal lainnya.

Selain produk, harga memiliki pengaruh yang besar terhadap kepuasan dan loyalityas konsumen. Jika mengacu pada nilai standardized loading factor keterjangkauan harga menjadi poin yang penting, yaitu menunjukkan bahwa sebagian responden memiliki keresahan terhadap harga makanan. Untuk dapat meningkatkan persepsi pelanggan terhadap harga, Waroeng Hotplate Odon dapat membuat kebijakan harga baru misalnya dengan membuat porsi baru dengan harga yang lebih terjangkau. Hal ini diperlukan agar pengunjung Waroeng Hotplate Odon yang mayoritas merupakan milenial dapat tetap menikmati pengalaman makan di restoran tanpa perlu mengkhawatirkan harga.

Pada bukti fisik terdapat dua hal yang perlu diperhatikan Waroeng Hotplate Odon yaitu penataan ruang dan lahan parkir karena nilai dari standardized loading factor lebih besar dari indikator lainnya. Waroeng Hotplate Odon dapat menata ulang ruang agar lebih menarik karena saat ini pengunjung restoran tidak hanya memperhatikan hidangan yang ditawarkan tetapi juga tata ruang dari restoran tersebut. Waroeng Hotplate Odon perlu menambahkan ornamen dan pencahayaan yang membuat pengunjung merasa nyaman dan mendorong mereka mengunggah suasana restoran ke media sosial. Selain menambah kepuasan pengunjung, Waroeng Hotplate Odon dapat memperoleh promosi dari para pengunjung yang mengunggah di laman media sosial. Lahan parkir juga memiliki pengaruh terhadap kepuasan pengunjung. Waroeng Hotplate Odon dapat melakukan beberapa cara terkait peningkatan lahan parkir seperti melebarkan area parkir ataupun menerapkan manajemen lahan parkir sehingga dengan lahan yang terbatas dapat menampung lebih banyak kendaraan.

Proses memiliki pengaruh terhadap kepuasan dan loyalitas pelanggan di Waroeng Hotplate Odon sehingga perlu diperhatikan oleh manajemen Waroeng Hotplate Odon. Berdasarkan data, waktu pelayanan dalam pemesanan dan penyajian makanan dapat diperbaiki. Untuk dapat mempercepat proses tersebut, Waroeng Hotplate Odon dapat membuat SOP agar setiap karyawan dapat memberikan pelayanan dengan standar yang ditetapkan dan cepat dalam melayani pelanggannya sehingga pada akhirnya dapat meningkatkan kepuasan serta loyalitas pengunjung dan meningkatkan intensitas pembelian ulang ke Waroeng Hotplate Odon. 


\section{KESIMPULAN DAN SARAN}

\section{KESIMPULAN}

1. Berdasarkan analisis Model Persamaan Struktural, secara umum bauran pemasaran (7P) memiliki pengaruh terhadap kepuasan dan loyalitas konsumen Waroeng Hotplate Odon pada penelitian ini. Terdapat 4 bauran pemasaran yang berpengaruh signifikan yaitu dari sisi produk, harga, bukti fisik dan proses.

2. Kepuasan yang tercermin dari kesesuaian harapan konsumen memiliki peranan yang sangat penting terhadap loyalitas konsumen Waroeng Hotplate Odon. Waroeng Hotplate Odon perlu meningkatkan pelayanan kepada konsumen agar semakin banyak konsumen yang puas terhadap pelayanan yang diberikan. Ketika seorang konsumen loyal terhadap restoran, mereka akan cenderung melakukan pembelian ulang dan juga merekomendasi Waroeng Hotplate Odon ke rekan atau keluarga. Meningkatkan loyalitas konsumen Waroeng Hotplate Odon dapat menjadi solusi dari penurunan jumlah pengunjung karena konsumen yang pernah datang akan kembali lagi serta merekomendasikan ke orang lain sehingga pada akhirnya akan mendapatkan konsumen loyal dan konsumen baru.

3. Waroeng Hotplate Odon sebagai sebuah restoran yang ingin mengembangkan usahanya perlu meningkatkan pelayanan dalam bauran produk yang tercermin dari citarasa makanan, variasi menu, dan tingkat kepedasan yang disajikan restoran. Selain itu, harga dan tata ruang serta ketersediaan lahan parkir masih menjadi pertimbangan bagi pelanggan Waroeng Hotplate Odon.

4. Generasi muda pada umumnya masih mempertimbangkan harga dalam memilih restoran karena sebagian besar pelanggan restoran ini adalah pelajar dan mahasiswa yang belum memiliki penghasilan pribadi. Interior di dalam restoran juga menjadi pertimbangan karena berpengaruh pada suasana nyaman yang dibangun dari pe- nataan ruang dan pencahayaan. Suasana yang nyaman membuat pelanggan ingin berada di restoran lebih lama dan melakukan kunjungan kembali. Bagi generasi muda yang berorientasi pada pengalaman, tata ruang restoran memiliki pengaruh terhadap kepuasan karena tata ruang yang baik dapat mendorong ulasan restoran di media sosial. Lahan parkir yang memadai penting untuk keamanan dan kenyamanan pelanggan selama berada di dalam restoran. Kecepatan pelayanan saat pemesanan menu dan proses pembayaran juga menjadi perhatian penting bagi pelanggan yang datang untuk menjadi pertimbangan puas dan loyal atau tidaknya pelanggan terhadap pelayanan yang diberikan oleh Waroeng Hotplate Odon.

\section{SARAN}

Berdasarkan kesimpulan yang telah dijabarkan, beberapa saran yang dapat diterapkan antara lain adalah sebagai berikut.

1. Untuk dapat meningkatkan kepuasan dan loyalitas pengunjung Waroeng Hotplate Odon yang mayoritas merupakan generasi muda, restoran dapat menambah bumbu baru untuk meningkatkan citarasa hidangan serta mempertahankan konsistensi rasa yang khas pada setiap pesanan pelanggan. Hal ini dapat diimplementasikan dengan baik jika restoran memiliki Standar Operasional Prosedur (SOP) yang diterapkan dengan baik pada bagian koki. Selain itu, variasi menu di Waroeng Hotplate Odon perlu ditambahkan agar pelanggan memiliki alternatif hidangan untuk dicoba ketika melakukan pembelian ulang. Tingkat kepedasan juga perlu ditambahkan yang semula hanya level 1 sampai 5 menjadi level 1 sampai 10 untuk membuat pelanggan penasaran dan mencoba level yang lebih tinggi setiap dating kembali ke Waroeng Hotplate Odon.

2. Dari segi harga, perbaikan yang bisa dilakukan adalah dengan memberikan opsi menu yang harganya lebih terjangkau bagi pelanggan yang mayoritas merupakan 
pelajar dan mahasiswa, seperti dengan menyediakan menu berukuran setengah porsi atau dengan menu sharing berukuran besar untuk 2-3 orang tetapi dengan harga yang lebih murah dibandingkan harga normal tiga porsi makanan.

3. Perbaikan dalam tata ruang dapat dilakukan dengan menambah ornamen dan pencahayaan untuk estetika interior restoran sehingga meningkatkan daya tarik Waroeng Hotplate Odon karena penataan ruang yang baik akan membuat pelanggan merasa nyaman. Selain keindahan tata ruang, kondisi lahan parkir juga perlu diperhatikan. Lahan parkir perlu diperluas untuk memberi kenyamanan bagi pelanggan yang membawa kendaraan sehingga mereka tidak khawatir akan kehabisan lahan parkir serta akan merasa aman untuk menitipkan kendaraannya selama berada di restoran.

4. Di samping perbaikan pada menu makanan, harga, dan tata ruang serta lahan parkir, pihak manajemen Waroeng Hotplate Odon juga perlu meningkatkan efisiensi dalam proses pemesanan menu dan proses pembayaran. Dalam hal ini, diperlukan SOP agar karyawan memiliki acuan dan target waktu pelayanan.

\section{DAFTAR PUSTAKA}

[Bappenas] Badan Perencanaan Pembangunan Nasional. 2013. Proyeksi Penduduk Indonesia 2010-2035 [Internet]. [diunduh 2019 Feb 20]. Tersedia pada: https://www.bappenas.go.id/files/541 3/9148/4109/Proyeksi_Penduduk_Indo nesia_2010-2035.pdf.

[Bapenda] Badan Pendapatan Daerah. 2017. Perkembangan Jumlah Restoran di Kota Bogor 2013-2017. Bogor (ID): Dispenda Kota Bogor

Barnes, NG. 2015. EWOM drives social commerce: a survey of millennials in US and abroad. Journal of Marketing Development and Competitiveness
[Internet]. [diunduh 2019 Apr 11]; 9(2): $\quad 36 . \quad$ Tersedia pada: http:/ / digitalcommons.www.nabusinesspress.com/JMDC/BarnesNG_ Web9_2_.pdf.

Bentler PM, Chou C. 1987. Practical issues in structural modelling. Sociological Methods and Research. 16(1): 78-117. doi.org/10.1177/0049124187016001004.

Debora Y. 2017. Ke mana mengalirnya uang para milenial [Internet]. [diunduh 2019 Mar 12]. Tersedia pada: https:/ / tirto.id/ke-mana-mengalirnyauang-para-milenial-cv76.

Doub AE, Levin A, Heath CE, LeVangie K. 2015. Mobile appetite: consumer attitudes towards and use of mobile technology in the context of eating behaviour. Journal of Direct, Data, and Digital Marketing Practice. 17(2): 114-129. doi:10.1057/dddmp.2015.44.

Fazira E. 2019. Spicy food trends in southeast asia [Internet]. [diunduh 2019 Jan 12]. Tersedia pada https://blog.euromonitor.com/spicyfood-trends-in-southeast-asia/.

Kuhns A, Saksena M. 2016. How millennial food purchase decisions compare to previous generations. Agricultural and Applied Economics Association Annual Meeting; 2016 Jul 31-Agt 2; Boston (US): [Economic Research Service, USDA]. [Nomor abstrak tidak diketahui].

Lam R, Burton S. 2006. SME banking loyalty (and disloyalty): a qualitative study in Hong Kong. International Journal of Bank Marketing. $\quad 24 \quad$ (1):3752.doi:10.1108/02652320610642335.

Latan H. 2013. Structural Equation Modeling Konsep dan Aplikasi Menggunakan Program LISREL 8.80. Bandung (ID) : Penerbit Alfabeta.

Lovelock C, Wirtz J, Mussry J. 2011. Pemasaran Jasa Perspektif edisi ke-7. Jakarta (ID): Erlangga.

Nazir M. 2005. Metode Penelitian. Jakarta (ID): Ghalia Indonesia. 
Saulo AA. 2016. Millennials and food. Food Safety and Technology. 63 (1): 1-3.

Wijanto SH. 2008. Structural Equation Modeling dengan LISREL: Konsep dan Tutorial. Jakarta (ID): Graha Ilmu. 